\title{
A EXECUÇÃO DO PNAE EM TRÊS MUNICÍPIOS NO TERRITÓRIO SUL LITORÂNEO DO ESPÍRITO SANTO
}

\author{
THE EXECUTION OF PNAE IN THREE MUNICIPALITIES IN \\ THE SOUTHERN COASTAL TERRITORY OF ESPÍRITO SANTO
}

\author{
Suely Ferreira da Cruz \\ Instituto Capixaba de Pesquisa, Assistência Técnica e Extensão Rural \\ suelsema@gmail.com \\ Thiago Rodrigo de Paula Assis \\ Universidade Federal de Lavras, Departamento de Administração e Economia, Lavras, \\ MG, Brasil \\ thiagoassis@ufla.br
}

\section{Resumo}

O Programa Nacional de Alimentação Escolar - PNAE é uma política que estimula a inserção dos produtos da agricultura familiar no cardápio escolar, por intermédio de entidades executoras, de forma individual ou coletiva. O objetivo do artigo foi analisar os problemas e potencialidades na execução da compra da agricultura familiar em três municípios do território Sul Litorâneo do Espírito Santo (Anchieta, Iconha, Rio Novo do Sul). A metodologia utilizou dados quantitativos e qualitativos por meio de análises de documentos disponibilizados pelas prefeituras, organizações de agricultores, ATER e trinta e nove pessoas entrevistadas (individual e grupo focal). Percebeu-se que o PNAE avançou nestes municípios, sendo que todos adquirem o mínimo de $30 \%$ exigido pela lei, chegando a $100 \%$. Porém, foram verificadas necessidades de melhoria nas chamadas públicas, no cumprimento dos contratos, nos preços e no respeito à sazonalidade dos produtos, e nas articulações entre envolvidos, inclusive internamente às organizações da agricultura familiar.

Palavras-Chave: Agricultura familiar. Comercialização. Organizações. Política pública.

\begin{abstract}
The National School Feeding Program - PNAE is a public policy that encourages the insertion of family farming products in the school menu, through executing entities, individually or collectively. The article aimed to analyze the problems and potentialities in the execution of family farming purchases in three municipalities of Southern Coastal Territory of Espírito Santo (Anchieta, Iconha, Rio Novo do Sul). The methodology adopted quantitative and qualitative data through analysis of documents provided by city halls, farmers' organizations, ATER and thirty-nine people interviewed (individual and focus group). It was noticed that the PNAE has advanced in these municipalities, and all acquire the minimum of $30 \%$ required by law, reaching up to $100 \%$. However, there was
\end{abstract}


a need for improvement in public calls, in the fulfillment of contracts, in prices and in respect for the seasonality of products, and in the articulations between those involved, including internally to family farming organizations.

Keywords: Family farming. Commercialization. Organizations. Public policy.

\section{Introdução}

Em 2009 foi promulgada a Lei 11.947/2009, determinando que no mínimo 30\% dos recursos repassados pelo Fundo Nacional de Desenvolvimento da Educação - FNDE ao Programa Nacional de Alimentação Escolar (PNAE) sejam destinados à compra de produtos da agricultura familiar. Essa é uma das principais políticas de comercialização para a agricultura familiar, com abrangência nacional. Ela contribui com a oferta de alimentos saudáveis às escolas, no aumento de produção e na diversidade de produtos, geração de ocupação e renda no meio rural (ELIAS, 2019).

Segundo o FNDE, em 2017 foi disponibilizado 3,918 bilhões de reais para o PNAE. Esse montante demonstra a importância da política para municípios brasileiros, onde existe presença marcante de agricultores familiares, como é o caso do Território Sul Litorâneo do Espírito Santo, que será tratado neste artigo. O território Sul Litorâneo foi criado em 2007 e abrange 08 municípios: Anchieta, Guarapari, Piúma, Iconha, Itapemirim, Marataízes, Presidente Kennedy e Rio Novo Sul, todos localizados ao Sul do Estado do Espírito Santo, que possui um passado marcado pela presença de jesuítas e pela forte migração europeia no decorrer do século XIX (MARTINS; VIEIRA, 2014).

Por outro lado, mesmo que o FNDE disponibilize esses recursos aos municípios e estados brasileiros, sua chegada a agricultores familiares tem encontrado barreiras. Muitos municípios ainda não atingiram os limites mínimos de compra da agricultura familiar exigidos pela legislação (SOUZA, 2020). Alguns estudos revelam que até 2017, havia municípios que ainda não realizavam chamada pública para aquisição de gêneros alimentícios da agricultura familiar (RIBEIRO; SILVA, 2018). Outros demonstram que esse valor é muito pequeno em relação ao universo de agricultores familiares e que poucos agricultores já são suficientes para atender a demanda, não sendo difícil atender essa exigência (GREGOLIN et al., 2017).

Em municípios onde a compra da agricultura familiar está consolidada há reclamações de que o montante do FNDE para a alimentação é baixo e que os municípios têm que disponibilizar recurso próprio para suprir as demandas nutricionais dos 
estudantes. Agricultores familiares também entram na discussão e afirmam que o percentual mínimo obrigatório de $30 \%$ do recurso deveria aumentar, bem como o valor de venda individual de vinte mil reais por agricultor. Isso demonstram que a política ainda está avançando e novos estudos podem contribuir para sua melhoria.

Por mais que qualquer legislação traga mudanças e adaptações percebe-se que em uma mesma região, dependendo da articulação local, o PNAE pode ou não ter sucesso. Neste sentido foram criadas várias normativas a fim de facilitar a execução do PNAE, considerado burocrático por muitos agricultores familiares, que só iniciaram sua experiência de inserção nas compras institucionais efetivamente em 2003, com o Programa de Aquisição de Alimentos (PAA).

Entre algumas das dificuldades apontadas na execução do PNAE estão aspectos ligados à mobilização, elaboração de editais, divulgação, atrasos em pagamentos, falta de produtos, entregas e descumprimento dos contratos pelas entidades executoras.

A compreensão da atuação dos diversos atores sociais é importante para a melhoria da execução da política, com adequação dos cardápios às pautas de alimentação regionalizada, aumento da oferta de produtos dentro dos limites municipais e garantia da segurança alimentar nos espaços rurais e urbanos, através da diversidade de produtos que compõem os editais de chamadas públicas, que podem ainda ser ofertados em outros canais de comercialização.

Outro ponto a destacar é a importância do diálogo entre os envolvidos na articulação e execução do Programa, que pode diminuir alguns problemas na elaboração e execução dos editais, pois muitas vezes são confeccionados por profissionais dos setores de compras, que desconhecem as especificidades da produção familiar e conduzem o processo de chamada pública como licitação, desconsiderando a sazonalidade, preços e a forma que os produtos serão entregues.

Diante da importância do PNAE, este artigo tem como objetivo analisar os problemas e as potencialidades na execução da compra da agricultura familiar em três municípios do território Sul Litorâneo do Espírito Santo, a fim de contribuir para a melhoria e avanço dessa política pública.

\section{Política pública e PNAE}

O enfoque sobre políticas públicas para a agricultura familiar após a década de 1990 se ampliou, dando origem a políticas em diversas áreas, destacando-se a 
Alimentação Escolar. A descentralização dos recursos financeiros, regionalização do cardápio escolar, a segurança alimentar e nutricional dos produtos ofertados, contribuíram para a reformulação do PNAE em 2009, fortalecendo as políticas focadas na comercialização da agricultura familiar (SARAIVA et al., 2013, TRICHES; SCHNEIDER, 2010).

Até a década de 1930, os alimentos ofertados aos estudantes em algumas escolas brasileiras eram adquiridos por meio de ações voluntárias, doações de comércios locais e de organizações sociais (CARVALHO, CASTRO, 2009). A partir de 1940, as chamadas caixas escolares arrecadavam dinheiro para fornecer alimentos aos estudantes, mas até esse momento eram ações pontuais, sem intervenção do Estado (CARVALHO, CASTRO, 2009; CHAVES, BRITO, 2006). Em 1955, no governo de Juscelino Kubitschek foi criada a Campanha da Merenda Escolar (CME), que passou a ser denominado de Programa Nacional de Alimentação Escolar (PNAE) em 1979. Apesar da institucionalização, o governo não conseguia atender a demanda, que era mantida por órgãos internacionais através da doação de produtos industrializados, oriundos dos Estados Unidos (CHAVES, BRITO, 2006). Em 1960 com a redução das doações, o governo passou a adquirir produtos brasileiros. A alimentação escolar foi promotora da indústria alimentar nacional, sendo os estudantes os principais consumidores. Segundo Castro (1977) o número de indústrias de alimentos no Brasil foi de 14.905 em 1940 para 46.815 em 1970. Na década de 70, a compra de produtos industrializados representava cerca de 52\% dos gastos com alimentação escolar, ofertando produtos como: paçoca; farinha láctea; sopa de feijão com macarrão, creme de milho com proteína texturizada de soja, creme de cereais com legumes, entre outros (CHAVES, BRITO, 2006).

Até 1993, a gestão do PNAE era centralizada pelo Ministério da Educação, que comprava os produtos através de licitação e distribuía em todo o país. A partir da Lei $n^{\circ}$ 8.913, de 12 de julho de 1994, ocorre a descentralização e a execução passa para as Secretarias de Educação dos estados e municípios (SARAIVA et al., 2013). A descentralização ocorreu por pressões de movimentos sociais e denúncias de desvios em licitações na esfera federal, desencadeada no governo Collor, como a "CPI da Fome" e auditoria do Tribunal de Contas da União (TCU). Essas investigações apontaram fraudes e irregularidades na aquisição e distribuição de alimentos, cartelização de setores das indústrias alimentícias que superfaturavam os preços, o que daria para comprar vários alimentos básicos e regionais (SHOTTZ, 2017). 
A partir de 1994, os produtos regionais começaram a surgir nos cardápios escolares. Mas a obrigatoriedade surge apenas em 2001, com a medida provisória $\mathrm{n}^{\circ}$ 2.178, determinando que $70 \%$ dos recursos do FNDE seriam para a compra de produtos que respeitassem os hábitos alimentares regionais e a vocação agrícola municipal. A medida foi reforçada por uma lista de alimentos básicos, que deveriam compor o cardápio escolar na resolução $\mathrm{n}^{\circ}$ 15, de 16 de junho de 2003 (SARAIVA et al., 2013).

De 1994 até 2009 a descentralização provocou mudanças profundas na alimentação escolar brasileira. A segurança alimentar e nutricional passou a ser discutida em diversas regiões do Brasil, destacando a atuação dos Conselhos Municipais de Desenvolvimento Rural Sustentáveis e Conselhos de Alimentação Escolar após o ano 2000, e diversos movimentos de agricultores familiares que cobravam políticas focadas na comercialização dos produtos da agricultura familiar.

Apesar dos caminhos percorridos na alimentação escolar brasileira, esses avanços não foram suficientes para a inclusão da principal categoria que produz alimentos no Brasil, que é a agricultura familiar, diretamente nos mercados institucionais. Mesmo com a descentralização dos recursos e a obrigatoriedade da inserção de alimentos regionais no cardápio, as compras continuavam sendo feitas em grandes empresas de gêneros alimentícios por meios das licitações.

A partir disso, percebe-se o potencial da alimentação escolar como política pública, que deveria avançar por meio da compra direta dos produtos da agricultura familiar em diversas regiões do Brasil. Porém os processos de licitação sempre excluíram os agricultores familiares dos mercados institucionais.

Em 2003, o governo de Luiz Inácio Lula da Silva criou o Programa Fome Zero, que era dividido em quatro eixos: ampliação do acesso aos alimentos, fortalecimento da agricultura familiar, promoção de processos de inserção produtiva e articulação e mobilização. No eixo do fortalecimento da agricultura familiar destaca-se a criação do PAA (ARANHA, 2010).

Com as chamadas públicas do PAA, instituído em 2003, o cenário começa a mudar, e os produtos dos agricultores familiares passam a ser comprados e doados para asilos, escolas, creches, etc. Essa experiência serviu para a reformulação do PNAE (SARAIVA et al., 2013; TRICHES; SCHNEIDER, 2010), que determinou a compra direta da agricultura familiar.

Com a lei n ${ }^{\circ} 11.947$ e a Resolução/CD/FNDE nº 38, ambas de 16 de julho de 2009, se estabelece um novo papel para agricultura familiar no PNAE (TRICHES; 
SCHNEIDER, 2010), determinando que no mínimo 30\% dos recursos repassados pelo FNDE deveria ser utilizado para a aquisição dos seus produtos (VILLAR et al., 2013).

Mesmo em regiões como o Sul do Brasil, que se destaca pela presença de organizações sociais da agricultura familiar (cooperativa e associações), havia poucas experiências de venda direta da agricultura familiar para alimentação escolar, descritas na literatura antes de 2003.

Dentre as poucas experiências com as compras da agricultura familiar antes de 2003, destaca-se o Vale do Rio do Sinos e Paranhana, no Rio Grande do Sul, onde as compras se iniciaram em 1998. O munícipio de Dois Irmãos efetivou a gestão local em 1995 e Rolantes em 1997, com articulação da Emater (Empresa de Assistência Técnica e Extensão Rural) e Fetag (Federação dos Trabalhadores na Agricultura). Em 2003, o comércio varejista de Rolantes fornecia $84 \%$ dos alimentos para a alimentação escolar, enquanto a agricultura familiar respondia por $16 \%$ do restante, já em 2008, 32\% dos recursos destinados para a alimentação escolar era para compras da agricultura familiar. Em 2003, todo valor alocado para compra de gênero alimentícios de Dois Irmãos era utilizado em atacadistas e varejistas, em 2009, passou-se a utilizar, aproximadamente, $60 \%$ do total do recurso federal para aquisição de gêneros da agricultura familiar (TRICHES, SCHINEIDER,2010).

Em São Lourenço, RS (CORRÊA; WIVES, 2018) e Francisco de Assis, RS (BALEM et al., 2014) foram registradas aquisições de produtos diretamente de agricultores familiares antes do PAA. Becker e Anjos (2010), também afirmam que isso ocorreu em determinados municípios do Rio Grande do Sul, onde se assistiu à emergência das primeiras experiências de compra de alimentos para a merenda escolar nas escolas públicas estaduais.

Historicamente o Brasil têm um dos seus principais gargalos na distribuição de renda, destacando-se com um dos países mais desigual do mundo. Scalon (2011), apresenta duas vias de redução das desigualdades: uma é a formação de novos modelos de desenvolvimento e a outra é definição e implementação de políticas que possibilitem uma distribuição mais equitativa dos bens e recursos sociais, que venham ampliar as oportunidades para um maior número de indivíduos. Entretanto, as crises econômicas do capitalismo e a redução do crescimento econômico pode comprometer novas políticas ou programas em andamento, pois o recurso tende a ficar cada vez mais escasso, sendo necessário uma divisão mais "justa" nas camadas mais pobres da sociedade. Neste 
sentido, priorizar categorias que gerem renda, ocupação e produção de alimentos pode ser uma opção eficiente, como a agricultura familiar e políticas em andamento como o PNAE.

A agricultura familiar no Brasil possui $77 \%$ dos estabelecimentos agropecuários compostos por agricultores familiares, a maioria localizados em municípios de pequeno porte distribuídos em todo território nacional (IBGE, 2017). Esses locais são potenciais para que políticas públicas como o PNAE avance e não fique apenas na compra de $30 \%$ determinado na legislação. Esses municípios têm parte significativas de suas rendas oriundas de programas de transferência de renda (aposentadorias, bolsa família) e produção de alimentos pela agricultura familiar. Segundo o Censo Agropecuário de 2017, são mais de 10 milhões de agricultores familiares, $67 \%$ do total de pessoas ocupadas na agricultura brasileira. Esses agricultores vêm enfrentando diversos problemas, destacando-se a comercialização dos seus produtos, que são produzidos em pequena escala.

Outro ponto da discussão é a possibilidade de promoção do desenvolvimento sustentável através do fortalecimento das atividades que geram rendas, saúde e bem estar aos envolvidos como: capitalização das famílias, aumento da produção, diversificação produtiva, regularização de agroindústria, incentivo a certificação orgânica, formação de grupos para gestão da comercialização, acesso a novos mercados, valorização da identidade produtiva, resgate aos hábitos, segurança alimentar e nutricional com novos cardápios escolares, consumo focado nas especificidades locais e regionais, sistemas de produção sustentáveis e ecológicos reproduzidos nas propriedades familiares do Brasil. Essas iniciativas devem ser pautadas nos programas e políticas públicas, uma vez que, ao encurtar, por exemplo, as cadeias de comercialização, o dinheiro que iria ser aplicado em outros locais circula dentro do município e região. Neste sentido o PNAE é uma política que visa contribuir para o desenvolvimento rural através da compra da agricultura familiar.

Silva et al (2020), avaliando a sustentabilidade em relação ao PNAE em Porto Velho, verificou a melhoria na capacidade de organização, de produção e comercialização dos agricultores familiares. Houve geração de emprego e renda, melhoria da qualidade de vida, além da venda do excedente de produção para outros setores. Os atores afirmam que o PNAE não deve ser analisado apenas pela ótica da venda, mas pela construção do processo, que no final acarreta numa espécie de investimento. Embora se pague um certo valor para a alimentação de cada aluno, esse mesmo valor é revertido para a sustentabilidade de toda uma cadeia produtiva. Mesmo que o PNAE seja um recurso 
mobilizável, ele é capaz de mudar a sociedade em direção a uma vida mais sustentável. Por isso, a importância de buscar compreender o funcionamento e os benefícios que são gerados de fato e as decisões que podem ser ponderadas para construção do desenvolvimento sustentável.

Apesar das potencialidades do PNAE como um novo canal de comercialização, aumento na renda das famílias, diversidade produtiva, melhoria da alimentação, etc., a mobilização social é determinante para o avanço da política, pois envolve diversos agentes, desde representantes dos agricultores, sindicatos, órgãos de Assistência Técnica e Extensão Rural (ATER) entre outros, que precisam estar em sinergia com a proposta de construção do desenvolvimento rural sustentável e do avanço da política nos municípios.

Após passar mais de dez anos da lei 11.947, muitos agricultores familiares ainda desconhecem o PNAE ou têm dúvidas sobre a sua execução, desconhecendo as questões legais e normas a serem seguidas para que as vendas ocorram (ASSIS et al.; 2016; 2019). Programas novos e desconhecidos não são aceitos com facilidade, o que torna importante o esclarecimento aos agricultores, pois no passado algumas ações governamentais não foram bem-sucedidas, gerando certa desconfiança quando o assunto é a venda para o poder público. Segundo Costa (2013), o PNAE requer planejamento e gestão, que poderia ser potencializado com capacitações dos atores sociais, que deveriam ocorrer com parceria entre o FNDE e entidades executoras, pois muitos ficam alheios às decisões políticas e às normas vigentes.

Após a reformulação do PNAE em 2009, os municípios que compõem o Território Sul Litorâneo do Espírito Santo começaram a se mobilizar para se inserir na política. O trabalho aborda a execução do programa, com intuito de contribuir, a partir das experiências analisadas para a melhoria do programa e sua expansão como política de desenvolvimento rural sustentável, com intuito de distribuição mais eficientes dos recursos para um dos grupos que mais gera ocupação no país, que são os agricultores familiares.

\section{Metodologia}

A pesquisa que deu origem a esse artigo ocorreu entre novembro/2016 e janeiro/2017 em 03 (três) municípios que compõem o Território Sul Litorâneo do Estado do Espírito Santo (MAPA 1): Rio Novo do Sul, Iconha e Anchieta. São municípios de pequeno porte e que têm agricultores familiares e suas organizações inseridas no PNAE. 


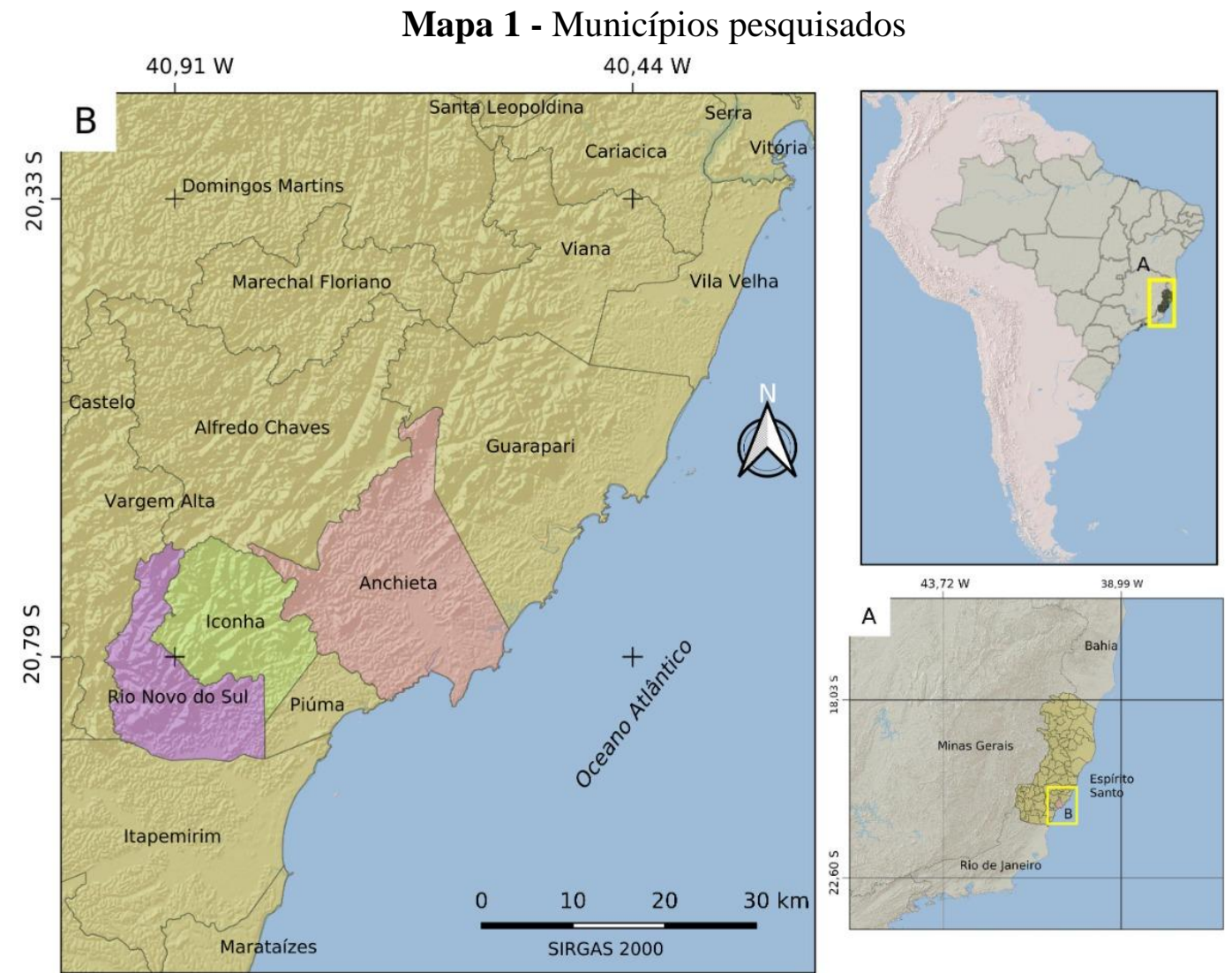

Fonte: IJSN - Instituto Jones dos Santos Neves (2021).

Rio Novo do Sul possui 11.325 mil habitantes (IBGE, 2010), 1.509 estudantes na rede municipal (SECRETARIA MUNICIPAL DE EDUCAÇÃO, 2017) e 1.054 na rede estadual (INEP, 2014). Em Iconha a população é de 12.523 habitantes (IBGE, 2010), com 1.780 estudantes em escolas municipais e 857 na rede estadual (INEP, 2014). E Anchieta possui 23.902 habitantes (IBGE, 2010), contando com o maior número de estudantes: 5.908 estudantes na rede municipal e 1.261 na rede estadual (INEP, 2014).

Os três municípios foram escolhidos por possuírem apenas uma organização de agricultores, pertencente ao próprio município, comercializando no PNAE municipal de maneira regular. Estas organizações possuem apenas agricultores familiares em seu quadro social, sendo um grupo informal em Rio Novo do Sul, uma cooperativa em Iconha e uma Associação em Anchieta. Dessa forma seria possível coletar os dados de maneira eficiente, acompanhar a evolução do programa e sua contribuição na região.

Os dados foram coletados através de análise documental, entrevistas semiestruturadas e grupos focais. A análise documental estudou os projetos de vendas e editais colhidos nas entidades envolvidas. As entrevistas semi - estruturadas foram realizadas com um total de quinze pessoas, sendo os responsáveis pelas organizações dos 
agricultores familiares, responsáveis pelos pagamentos, pelas chamadas públicas e extensionistas dos municípios.

A pesquisa contou ainda com três grupos focais, envolvendo vinte e quatro agricultores familiares, sendo seis ligados ao grupo Informal, oito à associação e dez à cooperativa. As entrevistas foram gravadas, com tempo médio de uma hora e três minutos em cada grupo. Os assuntos discutidos nas entrevistas, grupos focais e análise documental foram: produtos, entrega, chamadas públicas, preços, documentação, pagamentos, perfil dos agricultores, recursos liberados para o PNAE e relação entre os atores envolvidos.

Os dados secundários foram obtidos nos sites do FNDE, da Secretaria Especial da Agricultura Familiar, do Desenvolvimento Agrário (SEAD), Instituto Nacional de Estudos e Pesquisas (INEP) e documentos de prestação de contas das entidades executoras, referente aos anos de 2015 a 2020.

Os dados foram organizados de forma que possibilitaram as respostas aos problemas pesquisados. Esta etapa seguiu a proposta de Minayo (1996) que são: ordenação dos dados, classificação e análise final, a fim de atingir os objetivos do estudo.

\section{Resultados e discussão}

\section{Aplicação dos recursos na execução do PNAE}

Após dois anos de implantação do PNAE, os valores destinados a compra dos produtos da agricultura familiar superaram a exigência legal em alguns municípios do Território Sul Litorâneo do ES. Os valores mínimos de 30\% foram atingidos em $2011 \mathrm{em}$ Anchieta, 2012 em Iconha e 2014 em Rio Novo do Sul (GRÁFICO 1).

Gráfico 1 - Execução de Recursos do PNAE por município, entre os anos de 2011 e 2019

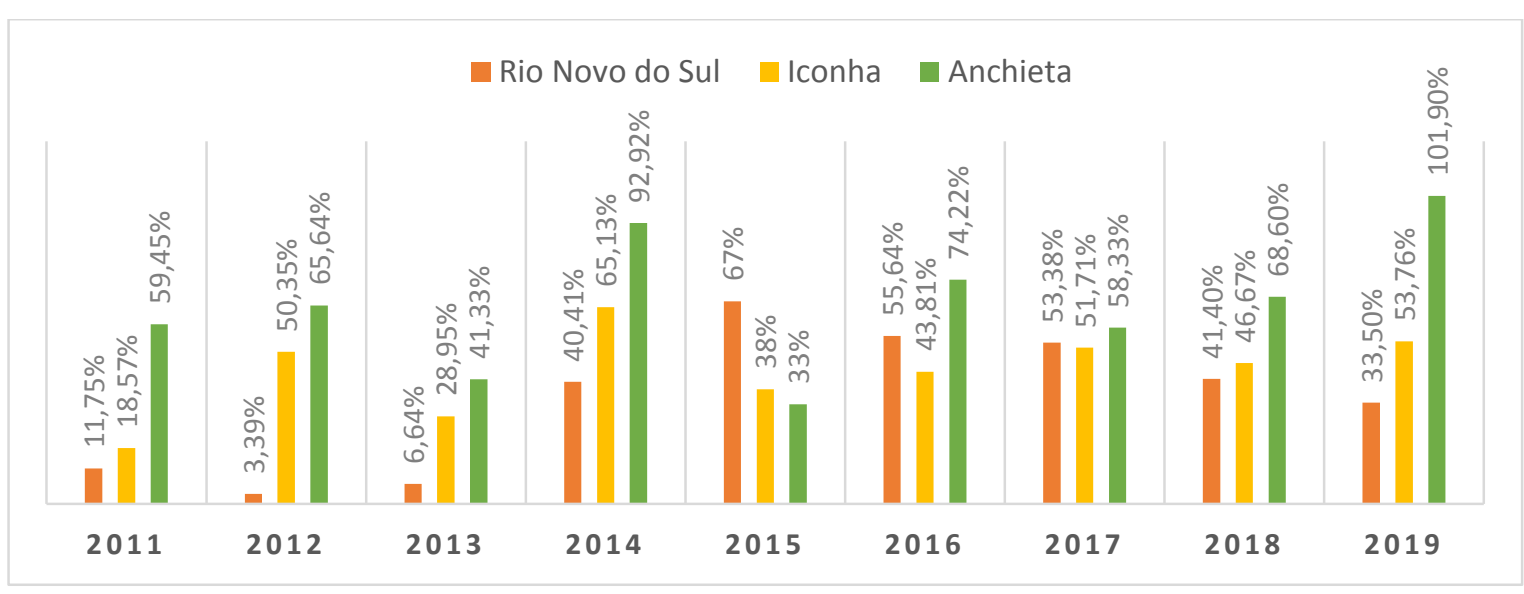

Fonte: FNDE (2017, 2020), Prefeitura Municipal (2020). 
Em Rio Novo do Sul, a participação no PNAE se dá por meio de um grupo informal. Após 2014, os valores se mantiveram acima da exigência legal. Em 2019, último ano analisado, o recurso repassado pelo FNDE para as escolas do município foi $\mathrm{R} \$ 164.330,00$. Desse total $\mathrm{R} \$ 55.095,10$ (33,5\%) foi destinado a compras de produtos da agricultora familiar local (TABELA 1).

Tabela 1 - Execução de Recursos do PNAE entre os anos de 2011 e 2019

\begin{tabular}{|c|c|c|c|c|c|c|c|c|c|}
\hline Município & 2011 & 2012 & 2013 & 2014 & 2015 & 2016 & 2017 & 2018* & 2019* \\
\hline \multicolumn{10}{|l|}{ Rio Novo do Sul } \\
\hline Recurso FNDE & $87.060,00$ & $108.144,00$ & $131.140,00$ & $130.980,00$ & $155.302,00$ & $152.891,06$ & $145.694,00$ & $155.080,00$ & $164.330,00$ \\
\hline Aquisição AF & $10.227,47$ & $3.666,62$ & $8.713,90$ & $52.926,80$ & $103.814,42$ & $85.072,15$ & $77.769,82$ & $64.215,69$ & $55.095,10$ \\
\hline$\%$ & 11,75 & 3,39 & 6,64 & 40,41 & 67,00 & 55,64 & 53,38 & 41,40 & 33,50 \\
\hline \multicolumn{10}{|l|}{ Iconha } \\
\hline Recurso FNDE & $122.280,00$ & $143.712,00$ & $164.020,00$ & $157.702,00$ & $171.230,00$ & $194.909,56$ & $188.182,00$ & $184.298,80$ & $191.447,38$ \\
\hline Aquisição AF & $22.706,65$ & $72.361,50$ & $47.483,33$ & 100.108 .08 & $64.641,46$ & $85.394,89$ & $97.313,21$ & $87.398,42$ & $102.934,88$ \\
\hline$\%$ & 18,57 & 50,35 & 28,95 & 65,13 & 38,00 & 43,81 & 51,71 & 46,67 & $53,76 \%$ \\
\hline \multicolumn{10}{|l|}{ Anchieta } \\
\hline Recurso FNDE & $390.120,00$ & $452.700,00$ & $570.380,00$ & $507.066,00$ & $610.650,00$ & $722.074,64$ & $731.376,00$ & $768.148,00$ & $691.934,00$ \\
\hline Aquisição AF & $231.921,26$ & $297.158,57$ & $235.761,00$ & $471.148,18$ & $202.415,88$ & $535.947,05$ & $426.609,10$ & $526.904,5$ & $705.094,08$ \\
\hline$\%$ & 59,45 & 65,64 & 41,33 & 92,92 & 33,00 & 74,22 & 58,33 & 68,6 & 101,9 \\
\hline
\end{tabular}
Fonte: FNDE (2017, 2020), *Prefeitura Municipal (2020).

Em Iconha a venda para o PNAE é feita por meio da Cooperativa dos Agricultores Familiares Sul Litorânea do Estado do Espírito Santo - CAFSUL, criada em junho de 2011, com sede no município. A CAFSUL conta com 197 cooperados de várias regiões do Estado e oferta seus produtos no PNAE em aproximadamente dez prefeitura da região e mais quarenta municípios, através das Secretarias Educação do Espírito Santo e Rio de Janeiro.

No ano de 2019 Iconha teve $\mathrm{R} \$ 191.447,38$ repassados pelo FNDE e o valor adquirido da agricultura familiar foi de $\mathrm{R} \$ 102.934,88$, correspondente a $53,76 \%$ do valor de recurso acumulado no ano (TABELA 1).

Em 2016 apenas três agricultores da CAFSUL constavam no projeto de venda repassado pela entidade executora. Segundo o presidente da CAFSUL havia mais agricultores que entregavam seus produtos à cooperativa, e que a inserção de poucos nomes era uma forma de agilizar o processo, pois o projeto era feito em nome da Cooperativa. 
Em Anchieta a comercialização no PNAE é feita pela Associação de Produtores de Banana e outros Produtos Agrícolas e da Agroindústria de Anchieta (APROBANA), composta de 70 associados. Fundada em 2006, tem por finalidade articular a comercialização da banana e quaisquer produtos agrícolas e agroindustriais no mercado local, regional e nacional. Também representa os associados na comercialização de insumos e da produção. Em 2016 tinha vinte e um agricultores participando da chamada pública da prefeitura.

Em Anchieta as aquisições da agricultura familiar no PNAE foram superiores à exigência mínima legal desde 2011, com destaque para 2019, em que as compras superaram os $100 \%$ dos recursos do FNDE (TABELA 1).

Ao analisar o comportamento da exigência mínima de $30 \%$ dos recursos repassados pelo FNDE, instituída pela Lei 11.947/2009 em diversas regiões do Brasil, verifica-se semelhanças no aumento gradual do PNAE.

Em análises feitas sobre o percentual médio aplicado na aquisição de gêneros da agricultura familiar no Rio Grande do Norte, em escolas estaduais na região Nordeste e no Brasil, Dias e Oliveira (2019) verificaram um crescimento gradual dos valores, saindo de $10 \%, 21 \%$, e $22 \%$ em 2010 para 32\%, 23\% e 29\%, respectivamente em 2012.

Thies et al (2016), analisando os recursos destinados às prefeituras do país, verificaram que 59\% compravam da agricultura familiar em 2011, passando para $77 \%$ das prefeituras em 2014. Em 2011 apenas 26,8\% das prefeituras compravam acima de 30\%. Em 2014 esse número passou para 39,5\%.

Neste sentido, Tascas et al (2020), analisando os dados de 2011 a 2017 no Território Alto Uruguai no Rio Grande do Sul, apontam que desde o início do PNAE, todos os municípios cumprem o mínimo exigido pela legislação. Na região as entidades municipais destinam $72,79 \%$ dos recursos do FNDE, adquirindo produtos da agricultura familiar, enquanto as entidades estaduais aplicam 37,37\% dos recursos. Este dado demonstra que as articulações locais têm seu papel fundamental na condução e implantação da política.

Em outras regiões do Brasil vários municípios têm dificuldade de aplicar a quantidade de recursos definidos na legislação. Souza (2020), analisando os dados de 2011 a 2015, na Paraíba percebeu que a maioria dos municípios não compram da agricultura familiar. $\mathrm{O}$ atendimento à exigência legal no PNAE também foi estudado por 
Ribeiro e Silva (2018), no Território de Identidade Médio das Contas, Bahia. Segundo os autores, dentre os municípios que realizavam Chamadas Públicas entre o triênio de 20152017, a maioria comprava acima dos 30\%, mas havia municípios do Território que não compravam da agricultura familiar, apontando a limitação na transferência de acesso à informação e a importância do controle social do recurso nesses municípios.

Mesmo com esse cenário diverso, em 2015 houve aumento de 83\% no número de municípios que atingiram a meta de $30 \%$ de recursos do PNAE para a Agricultura Familiar no Brasil, em relação a 2011 (NUNES et al., 2018).

O Território Sul litorâneo do Espírito Santo é parecido com outros territórios e regiões do Brasil, onde mesmo possuindo características produtivas e culturais semelhantes, o PNAE avança de forma diferente. Em Rio Novo do Sul apenas em 2014 a prefeitura conseguiu cumprir a legislação. Enquanto Anchieta atendeu a exigência em 2011.

Um ponto a refletir é que a legislação não deixa clara uma forma de penalizar e de cobrar de maneira efetiva a aplicação desse recurso. Por mais que haja dificuldade, isso não deveria ser visto como impossibilidade de execução da política em atingir os $30 \%$ de recursos repassados pelo FNDE. Esse percentual em municípios de pequeno porte é muito baixo em relação a quantidades de agricultores familiares existentes. Poucos agricultores inseridos no PNAE já seriam suficientes para se adequar à lei.

No Território Cantuquiriguaçu no Paraná observou-se que em vários municípios não precisariam de muitos agricultores para atender o mínimo de $30 \%$ do recurso destinado a agricultura familiar. Em alguns desses municípios, um ou dois agricultores atenderiam essa obrigatoriedade, considerando a cota máxima para cada agricultor, que é vinte mil reais. Entre os 20 municípios desse território, no município que recebeu mais recursos, sete agricultores já seriam suficientes para atender à legislação. Mesmo assim, entre 2010 - 2014 havia munícipios que não atendiam o mínimo exigido (GREGOLIN et al., 2017).

Gregolin et al (2017) destacam dois pontos que impactam no PNAE: a fonte própria de recurso do município para alimentação escolar e a possibilidade de aumento dos valores dos recursos repassados pelo FNDE. O valor destinado pelo FNDE não é suficiente para suprir as exigências nutricionais e a maioria dos municípios não tem o 
entendimento que esse recurso é complementar e que deveria aplicar recurso próprio para compra da alimentação escolar, uns acabam aplicando mais que outros.

No Território Sul Litorâneo do Espirito Santo foram levantados 40 agricultores nos projetos de venda das prefeituras. Em 2016, Rio Novo do Sul teve 16 agricultores no PNAE, em Iconha apenas 03 agricultores e Anchieta 21 agricultores. Gregolin et al (2017) afirmam que o PNAE também é uma política de complementação de renda e deveria promover a não concentração dos recursos em uma única família, e sim a distribuição ao máximo de fornecedores que fosse possível, por isso a importância de comprar acima dos $30 \%$ e de ter um cardápio variado, elaborado de acordo com a produção local, permitindo a compra de mais produtos e inserção de mais agricultores.

Diante do apresentado pelo estudo atual e pelos autores citados, a distribuição dos recursos da alimentação escolar é gradativa, com resultados promissores e variáveis em alguns momentos frente aos entraves encontrados na execução, como a chamada pública, atores envolvidos, organização formal e informal dos agricultores, formulação de preços, articulação e outros assuntos que serão abordados no decorrer deste artigo. E seu avanço nem sempre está ligado a produção agrícola da região ou local, ao número de agricultores e estabelecimentos rurais. São diversos fatores combinados, entre erros, acertos e ajustes que a política vai cumprindo seu papel. E por mais que atinja uma população ainda pequena, frente à quantidade de agricultores que existe, ela é fundamental para diminuir as desigualdades que também atinge os agricultores familiares distribuídos em todas as regiões do Brasil. A próxima sessão irá analisar aspectos ligados a execução do PNAE nos municípios estudados, a fim de melhorar o entendimento desse mercado institucional na agricultura familiar.

\section{O processo de execução do PNAE nos municípios estudados}

Um dos elementos essenciais para a execução da compra da agricultura familiar no PNAE é o planejamento e realização das chamadas públicas para a aquisição dos alimentos. A chamada pública é um instrumento legal que permite a comercialização dos produtos dos agricultores familiares para a alimentação escolar, dispensando os procedimentos licitatórios, nos termos do art. 14 da Lei $n^{\circ} 11.947 / 2009$, desde que os preços estejam em consonância com o mercado local por meio de pesquisas de preço. 
A chamada pública permite se adequar às especificidades dos produtos da agricultura familiar e contribui para que as diretrizes do PNAE sejam atendidas. É de responsabilidade da entidade executora e deve conter todas as informações relativas aos produtos: quantidade, preços, entregas, entre outras, para que os agricultores e suas organizações formulem seus projetos de venda.

A chamada pública envolve vários departamentos das entidades executoras. No caso das prefeituras de Rio Novo do Sul, Iconha e Anchieta, o processo inicia-se nas secretarias municipais de educação e seguem para outros setores administrativos.

Em cada um dos municípios estudados, os procedimentos para a elaboração e publicação do edital possuem algumas diferenças, em Rio Novo do Sul é realizada reunião entre agentes da ATER municipal, agricultores e a nutricionista do município, o que torna o processo mais participativo. Em Anchieta, a nutricionista faz o levantamento de produtos, que é apresentada ao CAE, em seguida é encaminhada para a Comissão de Agricultura do município, que envia para o setor de contabilidade para averiguar a disponibilidade financeira, retorna para a Comissão da agricultura que elabora a minuta e depois para o jurídico que autoriza a abertura do edital. Enquanto em Iconha, a lista sai da nutricionista, passa pela contabilidade que confere a disponibilidade de recursos e segue para o setor de licitação que elabora e divulga o edital.

Nos três municípios a divulgação do edital ocorre no Diário oficial do Estado e nos sites das prefeituras. Em Iconha e Rio Novo do Sul a notificação é feita em um jornal regional, na Secretaria de Educação e na Câmara Municipal. Em Rio Novo do Sul também é afixado um aviso no Ministério público, na Secretaria de Agricultura e no escritório local do Incaper.

Um dos problemas na elaboração do edital, citados nas entrevistas, está na cotação dos preços de referência, pois os produtos da agricultura familiar possuem preços diferentes dos encontrados nas cotações dos supermercados, principalmente os produtos agroindustriais e artesanais, produzido por uma família, comunidade, municípios ou até mesmo uma região. Esses produtos têm sua própria identidade e origem, possuem um custo elevado para atender aos padrões sanitários exigidos pela legislação. São produtos sem adição de conservantes, apresentam um prazo de validade menor, com necessidade de entrega toda semana, fracionamento e embalagem diferente do que o agricultor está acostumado a utilizar para comercializar seus produtos, o que faz com que os custos de 
produção sejam maiores que os praticados pelas grandes redes no comercio em geral. E mesmo que a legislação oriente a priorização dos preços das feiras livres, isso nem sempre acontece. Durante o estudo foi observado que a legislação não deixa explícito, como fazer a cotação nas feiras livres, que normalmente são formadas por bancas ou barracas, onde o agricultor e sua família individualmente comercializam sua produção.

Principalmente em municípios com feiras contendo poucos agricultores, isso dificulta a precificação pelos setores de compras dos municípios, pois há produtos que não são encontrados nas feiras livres e/ou que são produzidos por poucos agricultores, tendo apenas um agricultor vendendo esses produtos nas feiras, como biscoitos, pães caseiros e outros, que não têm conservantes e tem um prazo de prateleira menor. Ao precificar esses produtos, considerado o valor dos preços dos supermercados ou demais estabelecimentos comerciais, cujo a técnica de produção é diferente, sem adição de fretes, o tipo de material, composição do produto, embalagem e as exigências sanitárias que este procedimento exige, o custo de produção pode inviabilizar a participação do agricultor no PNAE, como foi observado durante o estudo.

A precificação dos produtos foi relatada como um problema por Triches e Schneider (2010), pois muitas vezes seguem a mesma lógica do varejo e atacado, que não se comprometem com a qualidade dos produtos. Além disso, os grandes atacadistas, na maioria das vezes, são abastecidos pela produção em grande escala e conseguem obter lucros através dos volumes de venda que fazem, aliados a isso conseguem manter estoques para abastecer o mercado nos períodos de entressafras, com preços menores.

Outro relato das entrevistas com os responsáveis pela chamada pública nos municípios é sobre a época e a frequência em que são publicados os editais, pois alguns produtos podem estar com os preços muito abaixo do que são praticados no decorrer do ano, em todos os municípios pesquisados é realizada apenas uma chamada pública por ano. Segundo Assis et al (2016), há produtos com oferta maior em determinadas épocas e menores em outra, fazendo com que os preços variem muito entre safras e entressafras. Neste contexto é difícil inserir essa variação em um edital de chamada pública realizado apenas uma vez por ano. Segundo os autores, um agricultor pode não se interessar em entregar um produto que custa $\mathrm{R} \$ 2,00$, sabendo que daqui a poucos meses ele custará o dobro. 
A elaboração de mais editais por ano poderia reduzir o problema e contribuir para uma precificação mais adequada, uma vez que os produtos agrícolas sofrem diversas oscilações de preço durante o ano. Porém, isso requer um planejamento bem criterioso por parte da entidade executora, pois nos municípios pequenos a mesma equipe é responsável por toda a compra do município e o processo demora muito ao tramitar pelos setores responsáveis. Isso pode prejudicar ainda mais os agricultores, com mais atrasos. Assis et al (2016) afirmam que a chamada pública pode ser burocrática para alguns agricultores, pois requer documentos e assinaturas de contratos, os quais os agricultores não estão acostumados. Triches e Schneider (2010) afirmam que a burocratização dificulta o acesso aos mercados e impede o avanço da política pública. Assim, torna-se importante que a entidade executora tenha um planejamento criterioso e que existem mecanismos para que as chamadas não se tornem um empecilho à participação dos agricultores. Diante desses desafios os agricultores e suas organizações precisam criar estratégias para se adequar as exigências legais do PNAE, atuando e participando dos espaços de debate e decisão, como por exemplo, os conselhos municipais.

O edital para chamada pública deve inserir os produtos locais, respeitando os preços e sazonalidade dos produtos. Além disso, cumprir os contratos é uma forma de garantir a permanência e aderência de agricultores no PNAE. Nos três municípios foram relatados casos em que o agricultor faz um cronograma para produzir, se comprometendo a entregar seus produtos, mas não teve seu pedido para fornecimento feito na época certa ou pego com atrasos. Os agricultores e as organizações, mesmo assim relatam que continuam entregando e dialogando com as instituições para tentar melhorar estes pontos. A maioria dos editais são lançados no início do ano, mas os pedidos e as entregas só ocorrem no meio do ano. Em locais em que os atrasos são constantes o agricultor vai se precavendo, acessando outros mercados, fazendo um plantio menor, entre outros.

A quantidade de produtos do edital acaba sendo apenas uma referência, pois a quantidade contratada nunca é entregue. Silva e Pedon (2015) fizeram o mesmo relato, estudando o PNAE. Isso aponta a necessidade de criar um mecanismo de controle para o cumprimento dos contratos, pois percebe-se que os municípios só se preocupam em atender os $30 \%$ exigidos pela legislação e não o que foi divulgado no edital e nos contratos firmados. 
Durante a pesquisa verificou-se que a formação do edital é uma etapa que exige um comprometimento maior dos envolvidos. Um dos principais aspectos é a necessidade de conhecer a realidade da agricultura familiar do local e inserir os agricultores nas discussões. Outro aspecto é que o processo ainda é considerado muito burocrático, seguindo caminhos que devem ser simplificados para que na prática a política avance. Em São Lourenço do Sul segundo Corrêa e Wines (2018), a burocracia é considerada excessiva até pelos agricultores com mais tempo no PNAE, pois têm que abrir mão das suas atividades e ir até os setores do município para acompanhar a tramitação documental da chamada pública.

Em todos os três municípios houve incialmente um trabalho envolvendo os extensionista do Incaper e no caso de Anchieta, da Secretaria de Agricultura do município. Entretanto, com a maior autonomia da APROBANA e a criação da CAFSUL, esses órgãos ficaram apenas na orientação produtiva e emissão das DAP's (Declaração de Aptidão ao Pronaf), que é um documento que identifica o agricultor familiar, podendo acessar diversas políticas públicas. Em Rio Novo do Sul desde o início a política é articulada pelos extensionistas do INCAPER, que orientam todos os processos, desde a produção, mobilização dos agricultores e a confecção do projeto de venda para concorrer a chamada pública. Além disso, os agricultores relataram a diminuição desses profissionais técnicos nos municípios, e a redução de recursos de custeio: como gasolina e reparos nos veículos, como fatores citados e que comprometem a assistência técnica e as visitas às propriedades, o que pode atrapalhar o andamento e execução da política e da produção rural, principalmente em municípios que a política é articulada pelos órgãos de ATER.

Outros pontos relacionados à execução do PNAE foram citados durante as entrevistas, destacando-se a carência de profissionais para atuar na recepção dos produtos, a ineficiência na mobilização dos agricultores, a incerteza dos agricultores nas vendas para os municípios, o espaço inadequado para armazenamento dos produtos adquiridos e a dificuldade em implantar os serviços de inspeção sanitária. Foi observado que há produtos da licitação, que poderiam ser produzidos nos municípios, através de uma política de incentivo em parcerias com instituições de ATER. Cabe destacar, a inexistência de um programa de treinamento e conscientização de profissionais, 
estudantes e demais envolvidos sobre a importância da agricultura familiar e seus produtos na alimentação escolar.

A dificuldade de entrega inviabiliza a participação dos agricultores, que tem a responsabilidade sobre as entregas e logística da produção (SILVA, PEDON, 2015; CORRÊA, WINES, 2018). Agricultores de baixa renda, sem meio de transportar seus produtos podem não ser beneficiados pela política, pois ao assinar o contrato esse compromisso fica com o agricultor.

Em trabalhos com mercados institucionais em Minas Gerais, Assis e colaboradores (2016) relatam que uma forma encontrada para aumentar a oferta de produtos a ser comercializado no PNAE em Divinópolis pela Associação de Pequenos Produtores da Agricultura Familiar de Divinópolis, apoiado pela Emater-MG, foi através de um projeto chamado "Mais Variedade", em que a organização oferecia insumos e sementes ao agricultor, que plantava o que ainda não possuía ou era oferecido em pequenas quantidades.

Os agricultores ponderam que alguns produtos devem ser adquiridos por meio de licitação, pois os agricultores não têm condição de ofertar e/ou mesmo adequar os produtos às normas que a legislação exige. "Peixe e carne é difícil para gente agricultor" (Agricultora J). A dificuldade de vender processados é um dos principais problemas enfrentados no PNAE. Um dos problemas está na necessidade de adequar agroindústrias e abatedouros à legislação sanitária, e de instalação do serviço de inspeção nos municípios. Segundo Assis e outros (2016), uma experiência interessante para superar essa barreira foi observado no município de Guapé - MG, onde, com o apoio da Prefeitura Municipal os agricultores familiares utilizavam o matadouro municipal e comercializam as carnes nos mercados institucionais. A assistência técnica voltada para a regularização sanitária é uma das dificuldades encontrada no PNAE (RIBEIRO, SILVA, 2018) e que inviabiliza o fornecimento principalmente de produtos agroindustrializados pela agricultura familiar, pois são procedimentos que exigem adaptações que possuem custo elevado e demanda conhecimento técnico e de legislação sanitária.

Os agricultores da APROBANA afirmaram que no início da implantação do PNAE os órgãos ligados à agricultura no município incentivaram bastante o plantio de várias culturas, mas sem saber como esses produtos seriam vendidos e se quantidade atenderia a demanda, por isso a necessidade de buscar outros mercados. 
Já em Iconha sede da CAFSUL, os agricultores relataram que a comercialização dos seus produtos depois da cooperativa ficou mais difícil, antes era feito por associações, mas com o aumento da demanda estimulado pela participação em vários editais do PNAE em outras prefeituras, principalmente de Vitória foi necessário criar a cooperativa, ampliando também a participação de agricultores de outros municípios. Ampliou as vendas de alguns produtos, mas os destaques são para banana, aipim e inhame. Na época da associação tinha mais facilidade em vender uma diversidade maior de produtos, e que hoje, mesmo preenchendo a planilha solicitada pela cooperativa no início do ano com os produtos que eles vão produzir, ela acabava não pegando efetivamente os produtos. Isso ocorre devido à redução dos produtos solicitados no edital, dificuldade de gestão das compras, atrasos nos editais, pagamentos e demora na assinatura dos contratos. O PNAE foi a ferramenta para a criação da CAFESUL, mas hoje, além do PNAE ela cresceu e atua em outros mercados.

Outro problema é não atentar para os calendários escolares, verificar os feriados e as paralisações que ocorrem durante o ano, isso já fez com que entregas fossem canceladas. Segundo os agricultores isso é fruto da falta de diálogo entre envolvidos, que deveriam ocorrer após o encerramento da chamada pública, conversar com as nutricionistas e fazer os ajustes, verificar as datas de entregas e repassar para os agricultores. Saraiva et al (2013) afirmam que a dificuldade de articulação entre os agentes é um dos entraves do PNAE.

Os entrevistados apontam também alguns problemas na forma de gestão da própria organização, que visando atender um número maior de cooperados, passou a pegar os produtos de várias pessoas, não obedecendo a planilha recebida no início do ano, discriminando o que cada agricultor planejaria entregar. Isso prejudica os agricultores que investiram e se dedicaram a produzir um produto de boa qualidade para atender o PNAE. Foi relatado durante as entrevistas com os cooperados que alguns agricultores foram para associações de outros municípios para comercializar seus produtos de qualidade no PNAE com preços mais atrativos.

Percebe-se assim que os agricultores vão criando formas de se articular à medida que a política vai se estabelecendo. Os elementos apresentados em relação à execução do PNAE nos três municípios pesquisados demonstram que há dificuldades por parte do poder público, dos agricultores e suas organizações, e na maior participação dos 
envolvidos. O trabalho de ATER na articulação da política pode ajudar a solucionar esses entraves.

\section{Considerações Finais}

O trabalho demonstrou que os municípios estudados executavam a política e compravam da agricultura familiar valores aproximados ou até superiores a 30\% dos recursos repassados pelo FNDE para a alimentação escolar. Mas apesar disso, ainda foram observados pontos que precisam ser melhorados para que facilitem a participação dos agricultores.

Do lado das entidades executoras é necessário um planejamento ajustado às especificidades da agricultura familiar, que respeite a sazonalidade dos produtos, com a publicação de novos editais antes do vencimento do anterior e precificação justa dos produtos. Realizar várias chamadas por ano, adquirir o acordado em contrato, estabelecer um diálogo entre os envolvidos no processo, criar projetos de incentivo à produção dos itens que ainda não são produzidos no município, fortalecer as parcerias com os diversos órgãos que podem auxiliar os agricultores familiares, ampliar o serviço de inspeção municipal e valorizar os serviços de ATER, são outros aspectos importantes a serem observados.

Entretanto, não pode se eximir a participação dos agricultores como protagonista neste processo, não só comercializando no PNAE, mas participando das discussões e nos espaços que a política é analisada, como nos Conselhos Municipais de Alimentação Escolar e de Desenvolvimento Rural dos municípios, principalmente cobrando transparência e controle social dos entes envolvidos. Em organizações como as cooperativas, as decisões recaem sobre a diretoria executiva, pois segundo o estudo há distanciamento e falta de diálogo entre os agricultores, diferentemente dos grupos informais, pois eles juntos criam suas estratégias de participação no PNAE com auxílio de entidades e órgãos de ATER.

Foi observado também que, apesar da possibilidade de ocorrência de problemas internos, a estratégia adotada para fomentar a participação dos agricultores no PNAE, por meio de organizações, tem grande relevância no cumprimento da política, seja uma organização formalizada ou não. 


\section{REFERÊNCIAS}

ARANHA. A. V. Um projeto transformado em estratégia de governo. In: (org.). Fome Zero: A experiência brasileira/ José Graziano da Silva; Mauro Eduardo Del Grossi; Caio Galvão de França - Brasília: MDA, 2010. P. 85-110.

ASSIS, T. R. P. et al. Mercados Institucionais e Agricultura Familiar: o Programa Nacional de Alimentação Escolar em 3 municípios de Minas Gerais. In: CONGRESSO DA SOCIEDADE BRASILEIRA DE ECONOMIA, ADMINISTRAÇÃO E SOCIOLOGIA RURAL, 54., 2016, Maceió. Anais... Maceió: 2016.

ASSIS, Thiago Rodrigo de Paula; FRANCA, André Guerra de Melo; COELHO, Amanda de Melo. Agricultura familiar e alimentação escolar: desafios para o acesso aos mercados institucionais em três municípios mineiros 1 Este artigo resulta de pesquisa apoiada pela Fapemig. Rev. Econ. Sociol. Rural, Brasília, v. 57, n. 4, p. 577-593, Dec. 2019.

BALEM, T. A.; SILVA, G. P.; SILVEIRA, P.R.C da. O impacto do mercado institucional da alimentação escolar no fortalecimento da agricultura familiar. Análisis Latinoamericano del Medio Rural nueva época, n.9, p. 183 - 206. 2014.

BECKER, C.; ANJOS, F. S. Segurança alimentar e desenvolvimento rural: limites e possibilidades do Programa de Aquisição de Alimentos da agricultura familiar, em municípios do sul gaúcho. Segurança Alimentar e Nutricional, v. 17, n. 1, p. 61-72, 2010.

BRASIL. MINISTÉRIO DA EDUCAÇÃO. FUNDO NACIONAL DE DESENVOLVIMENTO DA EDUCAÇÃO. MINISTÉRIO DA EDUCAÇÃO. Resolução/CD/FNDE No 38, de 19 de julho de 2009. Dispõe sobre o atendimento da alimentação escolar aos alunos da educação básica no Programa Nacional de Alimentação Escolar - PNAE.

CARVALHO, D. G; CASTRO, V. M. O Programa Nacional de Alimentação Escolar PNAE como política pública de desenvolvimento sustentável. Encontro da Sociedade Brasileira De Economia Ecológica, v. 8, 2009.

CASTRO, A. B. Observações sobre a indústria brasileira de alimentos. Revista de Administração de Empresas, v. 17, n. 6, p. 71-79, 1977.

CHAVES, L. G; BRITO, R. R. Políticas de Alimentação Escolar. Centro de Educação a Distância - CEAD, Universidade de Brasília, 2006.

CORREAA, E. C.S; WIVES, D. G. Influências e efeitos do PNAE na agricultura familiar em São Lourenço do Sul. COLÓQUIO-Revista do Desenvolvimento Regional, v. 15, n. 1, p. 17-37, 2018.

COSTA, J. M. . Política de alimentação escolar: tem caroço nesse angu? A gestão e o controle social do PNAE. 2013. 185 f. Dissertação (Mestrado em Educação) Universidade de Brasília, Brasília, DF, 2013. 
DIAS, T. F; OLIVEIRA, E. F. Agricultura Familiar, Políticas Públicas e Mercados Institucionais: uma Análise Exploratória do Programa Nacional de Alimentação Escolar-PNAE no Rio Grande do Norte. HOLOS, v. 5, p. 1-19, 2019.

ELIAS, Lilian de Pellegrini et al. Impactos socioeconômicos do Programa Nacional de Alimentação Escolar na agricultura familiar de Santa Catarina. Rev. Econ. Sociol. Rural, Brasília, v. 57, n. 2, p. 215-233, Jun. 2019.

FNDE. Programa Nacional de Alimentação Escolar. Dados da agricultura Familiar. Disponível em: https://www.fnde.gov.br/index.php/programas/pnae/pnaeconsultas/pnae-dados-da-agricultura-familiar. Acesso em: 29 ago. 2020.

FNDE. Programa Nacional de Alimentação Escolar. Dados Físicos e Financeiros do PNAE. Disponível em: https://www.fnde.gov.br/index.php/programas/pnae/pnaeconsultas/pnae-dados-fisicos-e-financeiros-do-pnae. Acesso em: 23 nov. 2020.

GREGOLIN, M. R. P et al. Potencialidades e fragilidades do programa nacional de alimentação escolar: PNAE no território Cantuquiriguaçu (PR). Revista Conexão UEPG, v. 13, n. 3, p. 548-567, 2017.

IBGE. Censo Agro 2017. Disponível em: https://censoagro2017.ibge.gov.br/templates/censo_agro/resultadosagro/pdf/agricultura familiar.pdf. Acesso em: 20 jul. 2020.

IBGE. Censo 2010. Disponível em: https://censo2010.ibge.gov.br/resultados.html. Acesso em: 20 jul. 2020.

IJSN. Instituto Jones dos Santos Neves. Mapas. Disponível em: http://www.ijsn.es.gov.br/mapas/. Acesso em 07 jul. 2021.

INEP. Sistema de Consulta a Matrícula do Censo Escolar - 1997/2014: Disponível em: http://matricula.educacenso.inep.gov.br. Acesso em: 22 fev. 2017.

MARTINS, L. R; VIEIRA, I. F. S. Política de desenvolvimento de territórios rurais: o caso do território sul-litorâneo no Espírito Santo. Geographia Opportuno Tempore, v. 1, p. 321-334, 2014.

MINAYO, Maria Cecília de Souza. O desafio do conhecimento: pesquisa qualitativa em saúde. In: O desafio do conhecimento: pesquisa qualitativa em saúde. 1996. p. 407 p-407 p.

NUNES, E. M. et al. O Programa Nacional de Alimentação Escolar (PNAE) como mecanismo de política de inclusão na agricultura familiar do Nordeste do Brasil. Revista Grifos, v. 27, n. 45, p. 114-139, 2018.

RIBEIRO, J. Souza; SILVA, W. S. Compras da Agricultura Familiar para atender ao PNAE no território rural médio Rio das Contas-BA (2015-2017). Revista Eletrônica Competências Digitais para Agricultura Familiar, v. 4, n. 2, p. 82-110, 2018. 
SARAIVA. E. B, et al. Panorama da compra de alimentos da agricultura familiar para o Programa Nacional de Alimentação Escolar. Ciência e saúde coletiva, Rio de Janeiro v.18 n. 4, abr. 2013.

SCALON, C. Desigualdade, pobreza e políticas públicas: notas para um debate. Contemporânea- Revista de Sociologia da UFSCar, v. 1, n. 1, p. 49-68, 2011.

SCHOTTZ, V. Programa Nacional de Alimentação Escolar (PNAE): controvérsias sobre os instrumentos de compra de alimentos produzidos pela agricultura familiar. 2017. 232 f. Tese (Doutorado em Ciências Sociais em Desenvolvimento, Agricultura e Sociedade). Instituto de Ciências Humanas e Sociais, Departamento de Desenvolvimento, Agricultura e Sociedade, Universidade Federal Rural do Rio de Janeiro, Rio de Janeiro, RJ, 2017.

SILVA, A. B; PEDON, N. R. Reprodução do campesinato através de políticas públicas voltadas para a agricultura familiar: a dinâmica do Programa Nacional de Alimentação Escolar (PNAE) em Ourinhos-SP (Reproduction of the peasantry through public policies focused on family...). REVISTA NERA, n. 26, p. 92-109, 2015.

SILVA, E. A .; PEDROZO, E.A .; SIENA, O. .; SILVA, T. N . A Lógica de Serviços do PNAE: Sustentabilidade da Agricultura Familiar. REVISTA CIÊNCIAS DA SOCIEDADE, [S. l.], v. 4, n. 7, p. 11-29, 2020. DOI: 10.30810/rcs. v4i7.1397. Disponívelem:http://ufopa.edu.br/portaldeperiodicos/index.php/revistacienciasdasocieda de/article/view/1397. Acesso em: 10 nov. 2020.

SOUZA, S. F. et al. Impactos do Programa Nacional de Alimentação Escolar (PNAE) no Estado da Paraíba. Revista de Ciências Agrárias, v. 43, n. spe1, p. 95-105, 2020.

TASCA, E; DEGGERONE. Z; PARIS, C. A. O fortalecimento da agricultura familiar no território Alto Uruguai (RS): implementação do Programa Nacional de Alimentação Escolar (PNAE). Revista Grifos, v. 29, n. 50, p. 103-125, 2020.

THIES, V. F.; GRISA, C.; SCHNEIDER, S.; BELIK, W. Potencial das compras públicas como Mercado para a agricultura familiar: Uma análise do PNAE entre 20112014. In: CONGRESSO DA SOCIEDADE BRASILEIRA DE ECONOMIA, ADMINISTRAÇÃO E SOCIEDADE RURAL, 54º., 2016, Maceió - AL.

TRICHES, M, R. SCHNEIDER, S. Alimentação Escolar e Agricultura Familiar: reconectando o consumo à produção. Saúde Soc. São Paulo, v.19, n.4, p.933-945, 2010.

VILLAR, B, S. et al. Situação dos municípios do estado de São Paulo com relação à compra direta de produtos da agricultura familiar para o Programa Nacional de Alimentação Escolar (PNAE) Epidemiol, v.16, n.1, p. 223-6, 2013.

Recebido em 22/03/2021.

Aceito para publicação em 30/05/2021. 